\title{
Ultrasensitive Detection of Unstained Proteins in Acrylamide Gels by Native UV Fluorescence
}

\author{
J an Roegener, ${ }^{\dagger}$ Petra Lutter, ${ }^{\ddagger}$ Ralf Reinhardt, ${ }^{\ddagger}$ Martin Bluggel, ${ }^{\ddagger}$ Helmut E. Meyer, ${ }^{\ddagger}, \S$ and \\ Dario Anselmetti*,t \\ Bielefeld University, Universitaetsstrasse 25, 33615 Bielefeld, Germany, and Protagen AG, Emil-Fligge-Str. 76 A, \\ 44227 Dortmund, Germany, and Ruhr University Bochum, Universitätsstrasse 150, 44801 Bochum, Germany
}

\begin{abstract}
Visualization of proteins inside acrylamide and other gels usually relies on different staining methods. To omit the protein-staining procedure, we visualized unstained proteins inside acrylamide gels by laser excitation with ultraviolet (UV) light $\left(280 \mathrm{~nm}, 35 \mathrm{~mJ} / \mathrm{cm}^{2}\right)$ and directly detected native UV fluorescence. In one-dimensional gels, a detection limit as low as $1 \mathrm{ng}$ for bovine serum albumin and $\mathbf{5} \mathbf{~ n g}$ for other proteins with a linear dynamic range ( 2.7 orders of magnitude) comparable to state of the art fluorescent dyes could be achieved. In addition, the application of this method to $20 \mu \mathrm{g}$ of a whole cell lysate separated in a two-dimensional gel showed more than 600 spots. Since protein labeling always represents a serious obstacle in protein identification technologies, the working efficiency with our procedure can be considered as a significant improvement for protein visualization and reproducibility in proteomics.
\end{abstract}

Currently, two-dimensional gel electrophoresis (2-DE) represents the technology most widely used to separate complex protein mixtures for subsequent differential comparison (proteomics). Proteins are separated according to their isoelectric point (pl) in the first dimension and according to their apparent molecular mass in the second dimension. This method was first introduced by Klose and O'Farrell in 1975.1,2 Continuous improvements in mass spectrometry (MS) over the last 10 years routinely allow protein spot identification in 2-DE. For proteomics research, 2-DE gels of different states (e.g., healthy vs diseased states) are acquired and compared in order to investigate biochemical processes (e.g., disease-causing mechanisms). The image analysis of several dozens of gels is a bottleneck in proteomics because of limitations in reproducibility of 2-DE and staining processes.

Currently, different staining methods for the visualization of proteins in a gel have been established. Staining after separation: Silver staining is the most sensitive standard detection method ( $1 \mathrm{ng}$ per band), ${ }^{3}$ but it is accompanied by problems, such as chemical modifications of the proteins. ${ }^{4}$ F urthermore, the staining and destaining procedures often result in a loss of protein and,

* Corresponding author. Phone: +49-521 106 5391. Fax: +49-521 1062959

E-mail: dario.anselmetti@physik.uni-bielefeld.de.

† Bielefeld University.

₹ Protagen AG.

$\S$ Ruhr University.

(1) Klose, J. Humangenetik, 1975, 26 (3), 231-243.

(2) O'Farrell, PH. J. Biol. Chem. 1975, 250 (10), 4007-4021.

(3) Williams, L. R. Biotech. Histochem. 2001, 76 (3), 127-132. therefore, in a loss of sensitivity for mass spectrometrical analysis. Additionally, each protein has an individual staining behavior due to its compositional properties. ${ }^{5}$ Another drawback is the low dynamic range of this staining method. Staining with Coomassie Brillant Blue G-250 (CBB) is widely used because it does not interfere with further $\mathrm{M} S$ analysis, however, at the cost of a lower detection sensitivity (20-60-fold). ${ }^{3}$ In contrast, labeling methods with fluorescent dyes are easier to handle and offer an improved dynamic range, but they are cost-intensive. ${ }^{6}$

Staining before separation: Labeling of proteins with fluorescent dyes before separation is a critical process, because the isoelectric point and the molecular mass of the proteins can be changed by this method as a result of the covalent modification. Radioactive labeling $\left({ }^{14} \mathrm{C},{ }^{3} \mathrm{H}\right)$ is the most sensitive method, ${ }^{3}$ but it is expensive, environmentally hazardous, and limited to biological experiments in which the organism can be incorporated with a radioactive medium (e.g., cell culture). Radioactive labeling prior to separation is possible becasue of little interference with the molecular mass and the isoelectric point. Both the experiment and the control can be compared within the same gel. ${ }^{7}$ A review of protein staining methods in electrophoresis is given by Williams. $^{3}$

First attempts of protein detection in 2-DE by using UV light $(280 \mathrm{~nm})$ have been published recently. Yamamoto et al. ${ }^{8}$ detected UV absorption at $280 \mathrm{~nm}$ at a sensitivity limit of micrograms. Koutny et al. published a setup for native fluorescence detection in 1-DE gels during separation using a UV-lamp $(253 \mathrm{~nm})$ with a sensitivity of several micrograms per band..$^{9} \mathrm{Kazmin}$ et al. ${ }^{10}$ measured the fluorescence excited at $280 \mathrm{~nm}$ by shifting the emitted fluorescence of tryptophan into the visible region by a chemical modification using $20 \%$ trichloracetic acid (TCA). They achieved a similar detection limit on the order of micrograms.

In this research paper, we present the first direct UV excitation and UV fluorescence detection of proteins in 2-DE at a very high sensitivity (1-5 $\mathrm{ng})$.

(4) Scheler, C.; Lamer, S.; Pan, Z.; Li, XP.; Salnikow, J.; J ungblut P. Electrophoresis 1998, 19 (6), 918-927.

(5) Harry, J. L.; Wilkins, M. R.; Herbert, B. R.; Packer, N. H.; Gooley, A. A.; Williams, K. L. Electrophoresis 2000, 21 (6), 1071-1081.

(6) Bumann, D.; M eyer, T. F.; J ungblut, P. R. Proteomics 2001, 1 (4), 473479.

(7) M onribot-Espagne, C.; Boucherie, H. Proteomics 2002, 2, 229-240.

(8) Yamamoto, H.; Nakatani, M.; Shinya, K.; Kim, B. H.; Kakuno, T. Anal. Biochem. 1990, 191, 58-64.

(9) Koutny, L. B.; Yeung, E. S. Anal. Chem. 1993, 65, 183-187.

(10) Kazmin D.; Edwards, R. A.; Turner, R. J.; Larson, E.; Starkey, J. Anal. Biochem. 2002, 1, 301 (1), 91-96. 


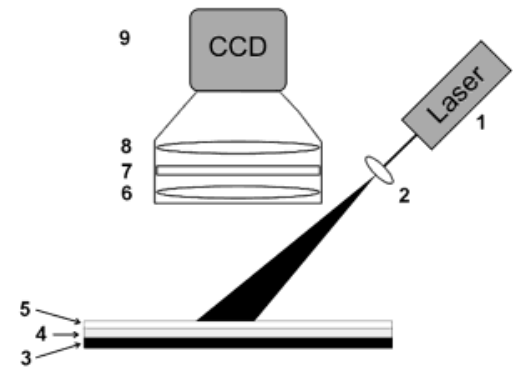

Figure 1. Experimental setup for UV detection of unstained proteins in gels: (1) UV laser, (2) spherical lens $(f=100 \mathrm{~mm}),(3)$ stainless steel plate, (4) acrylamide gel, (5) fused-silica window, (6) and (8) two Nikon lenses, (7) band-pass filter (300-375 nm), and (9) CCD camera.

\section{MATERIALS AND METHODS}

Electrophoresis and Staining. One-dimensional gel electrophoresis was performed on precasted $12 \%$ acrylamide gels in a tris-glycine-sodium dodecyl sulfate buffer system according to the manufacturer's instructions (Invitrogen, Karlsruhe, Germany). Separations of a four-protein mixture (carbonic anhydrase (bovine), $29 \mathrm{kDa}$; glyceraldehyde- 3-phosphate dehydrogenase (GAPDH) (rabbit), $36 \mathrm{kDa}$; serum albumin (BSA) (bovine), 66 $\mathrm{kDa}$; phosphorylase b (rabbit), $97 \mathrm{kDa}$; stock solution $100 \mu \mathrm{g} /$ $\mathrm{mL}$ of each protein) were run at different concentrations (1-500 $\mathrm{ng} /$ band) under reducing conditions.

Two-dimensional gel electrophoresis was performed as described $^{11}$ using a combination of carrier ampholyte isoelectric focusing (IEF) and sodium dodecyl sulfate polyacrylamide gel electrophoresis (SDS-PAGE). IEF was performed in rod gels containing $7 \mathrm{M}$ urea and $2 \mathrm{M}$ thiourea, 3.5\% acrylamide, $0.3 \%$ piperazine diacrylamide, and a total of $4 \%$ carrier ampholytes, $\mathrm{pH}$ 2-11. Cellular proteins of EA.hy $926^{12}$ whole cell lysates were prepared, and $\sim 20 \mu \mathrm{g}$ of protein was loaded at the anodic side of the IEF gels of $7 \mathrm{~cm}$ length and focused under nonequilibrium pH gradient electrophoresis (NEPHGE) conditions for $1842 \mathrm{Vh}$. SDS-PAGE was performed in gels containing $15 \%$ acrylamide using the IEF gels as stacking gels. The gel size was $70 \times 60 \times$ $1 \mathrm{~mm}^{3}$.

The gels were stored and fixed in 10\%acetic acid, 50\% ethyl alcohol, and $40 \%$ tridest water for 2 days to 3 weeks at $4{ }^{\circ} \mathrm{C}$. To reduce the background fluorescence, the gels were washed for $45 \mathrm{~min}$ in $50 \mathrm{~mL}$ of tridest water before the detection process and put on a $10 \mathrm{~cm} \times 10 \mathrm{~cm}$ stainless steel plate. The gel was covered by a fused-silica window to prevent drying and coiling up.

In addition, control gels were stained with silver ${ }^{13}$ and visualized using a white-light scanner (UMAX PowerLook 2100XL, U max Systems GmbH, Willich, Germany).

Setup. The experimental setup ${ }^{14}$ was based on a UV excitation source and a UV detection system with a spectral range in the deep UV (laser, 240-300 nm; CCD, 190-1000 nm; fluorescence filter, $300-375 \mathrm{~nm}$ ) (Figure 1). The excitation light was generated by a frequency tripled Ti:SA laser (Tsunami, Spectra Physics, U.S.A.) running at $840 \mathrm{~nm}, 80 \mathrm{M} \mathrm{Hz}$ of 100 -fs pulses creating a quasicontinuous wave $(\mathrm{cw})$ light of $280 \mathrm{~nm}$ with $150 \mathrm{~mW}$. The

(11) Klose, J. M ethods Mol. Biol. 1999, 112, 147-172.

(12) Edgell, C.-J. S. Proc. Natl. Acad. Sci. U.S.A. 1983, 80, 3734-3737.

(13) Heukeshoven, J.; Dernick, R. Electrophoresis 1988, 9, 28-32.

(14) Patent application CH 1344/ 02.
(A) UV detection

(B) Silver stain

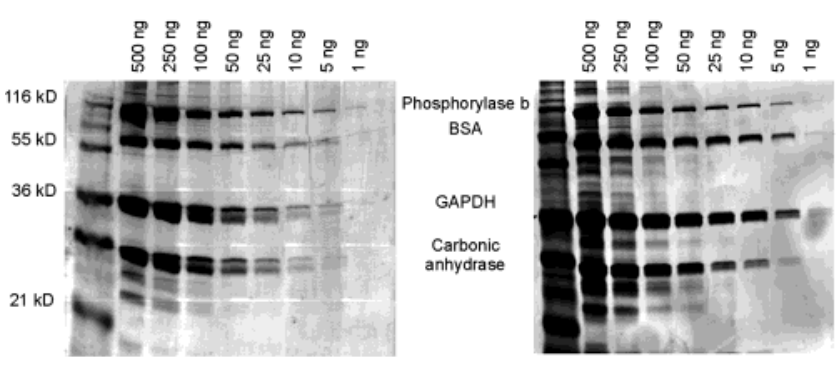

Figure 2. Comparison of UV detection and silver staining of proteins. A mixture of four proteins (carbonic anhydrase $(29 \mathrm{kDa})$, GAPDH (36 kDa), BSA (66 kDa), and phosphorylase $b(97.4 \mathrm{kDa})$ ) was loaded onto two gels that were prepared identically. Proteins were detected with (A) UV detection and (B) silver stain following scanning (visible spectra). The proteins were loaded as follows: lane 1, molecular mass standard; lanes 2-9: 500, 250, 100, 50, 25, 10, 5 , and $1 \mathrm{ng}$ of each protein. UV exposure at $280 \mathrm{~nm}$ was $35 \mathrm{~mJ} / \mathrm{cm}^{2}$.

irradiation area was set to $1 \mathrm{~cm}^{2}$ at $35 \mathrm{~mW} / \mathrm{cm}^{2}$ and imaged by two lenses (UV Nikkor, $105 \mathrm{~mm}$, f\#4.5, Nikon) onto a UV-sensitive CCD camera (QE > 65\% Dyna Vision Lavision Biotec, Germany). To block the excitation light from the CCD camera, a UV bandpass filter (300-375 nm, Edmund Scientific, U.S.A.) was incorporated.

The maximum sample size was limited to $100 \mathrm{~mm} \times 100 \mathrm{~mm}$ (4 in $x 4$ in). After each exposure ( $1 \mathrm{~s}$ ), the sample was moved manually on a $1-\mathrm{cm}$ spaced $10 \times 10$ grid for sequential image aquisition. Thereafter, the images were arranged, corrected for uneven excitation intensities, and compressed to a resolution of 260 dpi by a commercial software (D avis 6.2, LaVision, Goettingen, Germany). The CCD dynamic range of 16 bit has been enlarged to a theoretical value of 22 bit by averaging over 64 pixels. In fluorescence detection, proteins give bright signals, and the background is dark. For better comparison with silver stained gels, all presented fluorescent images were digitally inverted.

\section{RESULTS AND DISCUSSION}

Four independent 1-DE gels with four different proteins in concentrations ranging from 1 to $500 \mathrm{ng} /$ band were measured (Figure 2).

In all 1-DE gels, we observed a detection limit of $5 \mathrm{ng}$ for each protein. For BSA, the detection limit was even lower, at $1 \mathrm{ng}$. Control gels with silver staining exhibited a detection limit of 5 $\mathrm{ng}$ for carbonic anhydrase and $1 \mathrm{ng}$ for the other three proteins (GAPDH, BSA, Phosphorylase b).

In addition, two 2-DE gels $\left(6 \times 7 \mathrm{~cm}^{2}\right)$ loaded with $20 \mu \mathrm{g}$ of protein (Figure 3 ) and two gels loaded with 40 of $\mu$ g protein were analyzed. In Figure 3, a comparison between an UV-analyzed 2-DE minigel ( $20 \mu \mathrm{g}$ of protein) (A) with an identically prepared silver stained minigel $(B)$ is presented. Spot detection with a commercial software (ImageM aster 2D Elite, Amersham Biosciences, Freiburg, Germany) yielded 600 and 700 protein spots for UV and silver staining, respectively. The difference in the total number of spots can be explained by the different sensitivity of the UV detection method in the present setup.

The reason for the low limit of UV detection is mainly based on the strong fluorescence from the aromatic amino acid tryp- 
(A) UV detection
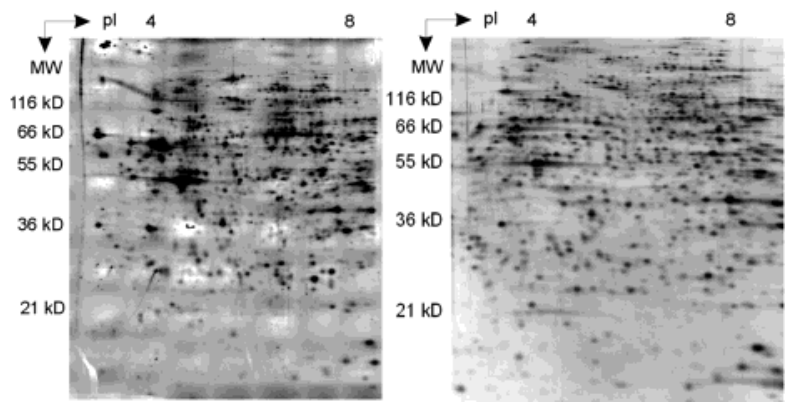

Figure 3. 2-DE spot pattern of EA.hy 926 whole-cell lysate. A 20$\mu \mathrm{g}$ portion of protein was loaded onto 2-DE gels with dimensions of $6 \times 7 \mathrm{~cm}^{2}$. (A) UV detection, inverse contrast representation $(600$ spots). The exposure was $35 \mathrm{~mJ} / \mathrm{cm} 2$. (B) Silver stain on identically prepared gel (700 spots).

tophan ${ }^{15}$ in combination with proper UV transparency and low background fluorescence from the gel. In 1DE gels, the protein fluorescence signal was always proportional to the protein amount, resulting in a linear dynamic range of 9 bit or 2.7 orders of magnitude $(1-500 \mathrm{ng})$. This compares well with state-of-the-art fluorescent dyes. ${ }^{16}$

The sensitivity and dynamic range are limited by the background fluorescence of the gel, whereas photobleaching of the proteins represents only a minor limitation.

To discuss the limit of this method, we have to consider the fluorescence brightness of the involved amino acid side chains and their abundance in proteins. The fluorescence brightness of tryptophan is roughly 10 times stronger than tyrosine. Since smaller proteins are typically not present in a 2-DE gel, a database search on 1026890 proteins with molecular mass larger than 10 kD was performed (NCBInr 9.23. 2002). Of all proteins larger than $10 \mathrm{kD}, 90.5 \%$ contain at least one tryptophan and should be detected well. Another $9 \%$ contain at least one tyrosine, which will be detected at lower sensitivity. Only $0.5 \%$ contain neither tryptophan nor tyrosine (predominantly small proteins) and cannot be detected by this method.

We detected the proteins offline after separation. Imaging during separation could be distorted by the running buffer. The

(15) Lakowicz, J. R. Protein F luorescence, Principles of F luorescence Spectroscopy; Plenum Publishing Coorporation: New York, 1983; pp 342-342.

(16) Lopez, M . F.; Berggren, K.; Chernokalskaya, E.; Lazarev, A.; Robinson, M .; Patton, W. F. Electrophoresis 2000, 21 (17), 3673-3683. fluorescence properties of a protein depend on the solvent as well as on $\mathrm{pH}$. We performed SDS-PAGE followed by fixation and washing with tridest water, resulting in a gel at approximately neutral $\mathrm{pH}$ where some SDS may be left. The fluorescence background signal could not be reduced by further washing.

Direct UV detection of proteins offers many advantages, as compared to conventional staining methods, which result in a loss (modification) of the proteins for further analysis. The proteins can be detected without any staining and destaining. For this reason, modifications of the proteins can be excluded. Furthermore, a direct quantification of the protein amount is possible without staining-dependent variations of the signal intensities.

Compared to all staining methods, washing out of proteins is reduced to a minimum. Conclusively, more proteins in amount and type are available for M S. And last but not least, this method is faster, environmentally safe, and consumable costefficient.

\section{CONCLUSION}

In this paper, we present the first direct UV fluorescence detection of unstained proteins in gels at low-nanogram sensitivity. Image aquisition due to direct UV fluorescence detection of proteins omits the staining procedure and represents, therefore, a promising alternative for routine laboratory work.

Although the laser used in this investigation is an expensive part of the setup, the use of a UV lamp instead can make the setup more cost efficient. ${ }^{9}$

$M$ ajor efforts have been made toward the automation of gel image analysis and comparison on one hand and of spot excision and preparation for mass spectrometric analysis on the other. But still, little attention has been paid to the automation of the staining and image capture process. The combination of a stainless spot detection and an automated spot excision would be another milestone in the automation process in proteomics.

\section{ACKNOWLEDGMENT}

This work has been supported by the Federal M inistry of Education and Research (BMBF) and the project "SCREEN". We acknowledge technical support from Stephan Woermer, Harald Schulz, and Gerd Wiebusch. 